\title{
A new ice thickness and bedrock data set for the Greenland ice sheet.
}

\author{
R.L. Layberry, J.L. Bamber, \\ Bristol Glaciology Centre, Centre of Geographical Sciences, University of Bristol, Bristol BS8 1SS, U. K. \\ Email: j.l.bamber@bristol.ac.uk, Phone 441179289000 \\ S.P. Gogenini, \\ Remote Sensing Labs, University of Kansas, Lawrence, KS 66045, 785/864-2700, U.S.
}

\begin{abstract}
Ice thickness data collected between 1993 and 1999 using a coherent ice penetrating radar system developed at the University of Kansas have been combined with data collected by the Technical University of Denmark in the 1970's to produce a new ice thickness grid for Greenland. Cross-over analysis was used to assess the relative accuracy of the two data sets and they were weighted accordingly and interpolated onto a regular grid using an optimal interpolation procedure. A high resolution land-ice mask was used to help constrain the interpolation of the ice thickness near the ice sheet margins where, in the past, the relative errors have been largest. The ice thickness grid was combined with a new digital elevation model of the ice sheet and surrounding rock outcrops to produce a new bed elevation data set for the whole of Greenland.
\end{abstract}

Relative measurements of the reflectivity of the bed/ice interface were extracted from the 1990's data to show areas of potential basal melting, a pre-requisite for basal sliding.

\section{INTRODUCTION}

In 1991, a research effort to measure the surface elevation of Greenland using laser altimeter data was begun as part of a wider effort to determine the mass balance of the ice sheet. In 1993, a $150 \mathrm{MHz}$ radar echo sounder, developed and operated by the University of Kansas was included on the airborne survey, and since 1993 up to and including 1999, yearly surveys have yielded a wealth of ice thickness data which have been disseminated for general use. Here we report on the use of the thickness data, in conjunction with a data set from the 1970's and the latest Digital Elevation Model (DEM) to interpolate a new ice thickness and bedrock data set. The data from the 1970's is of markedly lower quality than that of the 1990's though the earlier data set is able to fill in many of the gaps of the later and its lower accuracy is accounted for in this study.

\section{RADAR SYSTEM}

The coherent depth sounder which produced the results transmitted a $150 \mathrm{MHz}$ chirped, 1.6 microsecond pulse with a peak power of $200 \mathrm{~W}$. The equipment and various improvements to it is described in detail elsewhere [1,2]. Positioning was via kinematic GPS and a precision laser altimeter system. The separate transmit and receive antenna consisted of a four-element, half wavelength dipole array.
The returned signal was amplified with an end to end gain of $95 \mathrm{~dB}$ and had a resolution in ice of $5 \mathrm{~m}$. The signal was detected coherently, providing In-phase and Quadrature components which were digitised at a sample rate of 18.75 Msamples/s. Integration was performed over 256 consecutive pulses and the power in each record computed $\left(\mathrm{I}^{2}+\mathrm{Q}^{2}\right)$ before being further integrated over 4 data records.

The depth of the bedrock was computed by the number of pixels between the top and bedrock return, with each pixel representing $4.494 \mathrm{~m}$ of travel though the ice. The returns were picked manually, representing an initial quality control. This was performed at the University of Kansas and it was in this form that the results were made available.

The 1970's data were collected by the Technical University of Denmark using a $60 \mathrm{MHz}$ echo sounder, analogue recording technology and an inertial navigation system [3].

\section{DATA EXTENT, QUALITY AND FILTERING}

The 1970's and 1990's flight-lines are shown in Fig. 1. Both data sets are extensive, though the data from the 1970's is sparser along flight-lines (average spacing $1 \mathrm{~km}$ ) than the 1990 's (average spacing $150 \mathrm{~m}$ ), with the 1970's data containing approximately 30000 thickness data points and the 1990's data almost 700000 . Across track spacing is on the order of $20 \mathrm{~km}$.

Cross-over analysis was used to assess the accuracy of the thickness measurements, both for internal consistency and for consistency between data sets. The 1970's data had an average cross-over difference of $130 \mathrm{~m}$, due primarily to errors in the navigation data. The 1990's data had an average cross-over anomaly of only $15 \mathrm{~m}$ once some erroneous data had been removed (caused by errors in the navigation data).

The higher radar velocity through the upper firn layer compared with solid ice was compensated for by adding 10 $\mathrm{m}$ to the estimated ice thickness.

The data were gridded onto a polar stereographic projection using a linear distance weighting method, resulting in a quasi-regular 301 by 561 grid, representing a cell spacing of $5 \mathrm{~km}$. The thickness at each grid point was given by the weighted average of the data within the search radius of the 
cell centre and the exact grid point position by the similarly weighted averages of their positions. The 1990's data were weighted 10 times greater than the 1970's data, based on the cross-over analysis. This procedure reduced the quantity of data used in the interpolation, decreased the disparity between along and across track spacing, and allowed filtering on the basis of the resulting grid point standard deviations.

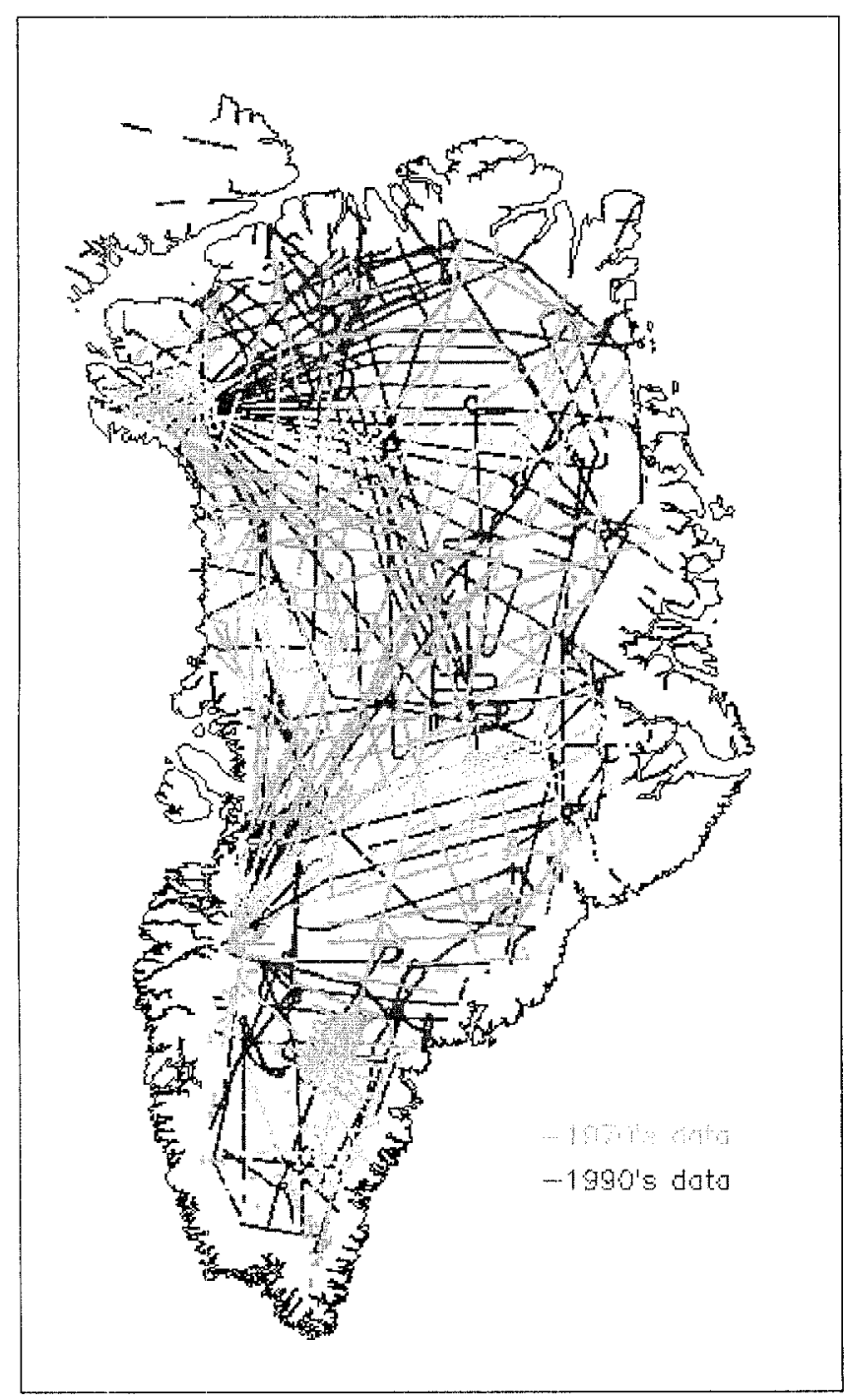

Figure 1: Flight-lines of the thickness data sets

Initial filtering involved the removal of gridded data points with only one contributing depth estimate. This removed a small amount of 1990's grid points that were likely due to errors in the navigation data. Discrimination against grid points with higher numbers of contributors would have significantly reduced the amount of sparser 1970's data used.
The average standard deviation in thickness at the grid points was $50 \mathrm{~m}$ with the higher values being concentrated around the eastern ice sheet margin where the topography is the most extreme. Calculation of along track standard deviations in thickness of the unaveraged data showed a strong correlation with the ice thickness, with the thinner ice having considerably greater standard deviations. Histograms of the standard deviations for different thickness bands, gave distributions which were nominally Gaussian. They also included points with anomalously high standard deviations that are potentially erroneous and have subsequently been removed from the data by the use of a thickness dependent cut-off at a point where the distribution is $1 \%$ of its maximum value. This removed $2 \%$ of the gridded data.

Much of the gridded data consisted of either points wholly contributed to by either 1990's or 1970's depth estimates and this lead to potential errors where less accurate 1970's data lay close to 1990 's data. Results from the interpolation in this case (especially where flight-lines from the different data sets are close to parallel) could give anomalously high local thickness gradients. At distances of 3 cells away from 1990 's data, the errors in the 1970's data would not cause anomalously high gradients and so gridded data points consisting entirely of 1970 's data closer than 3 cells to 1990 's data were removed.

The co-ordinates of non ice sheet points were finally appended to the data from a high resolution $(\sim 2 \mathrm{~km})$ land ice mask to act as a zero ice thickness boundary condition at the margins.

\section{INTERPOLATION}

The quasi regular grid was interpolated onto a 301 by 5615 $\mathrm{km}$ grid using ordinary kriging. This method was chosen due to the great range in spatial density of data points, with which kriging copes well [4].

In conjunction with the latest and most accurate DEM [5], the bedrock topography can be inferred with hitherto unsurpassed accuracy and this is shown in Figure 2.

It can be seen that a significant portion of the ice-sheet is grounded below sea level. These areas cover a substantial part of the interior where ice thicknesses are greatest, lowering the bedrock elevation, through isostatic compensation, by about $1000 \mathrm{~m}$. There are, however, several marginal areas on the north and north east coast where the bedrock elevations are more than $200 \mathrm{~m}$ below sea level. 


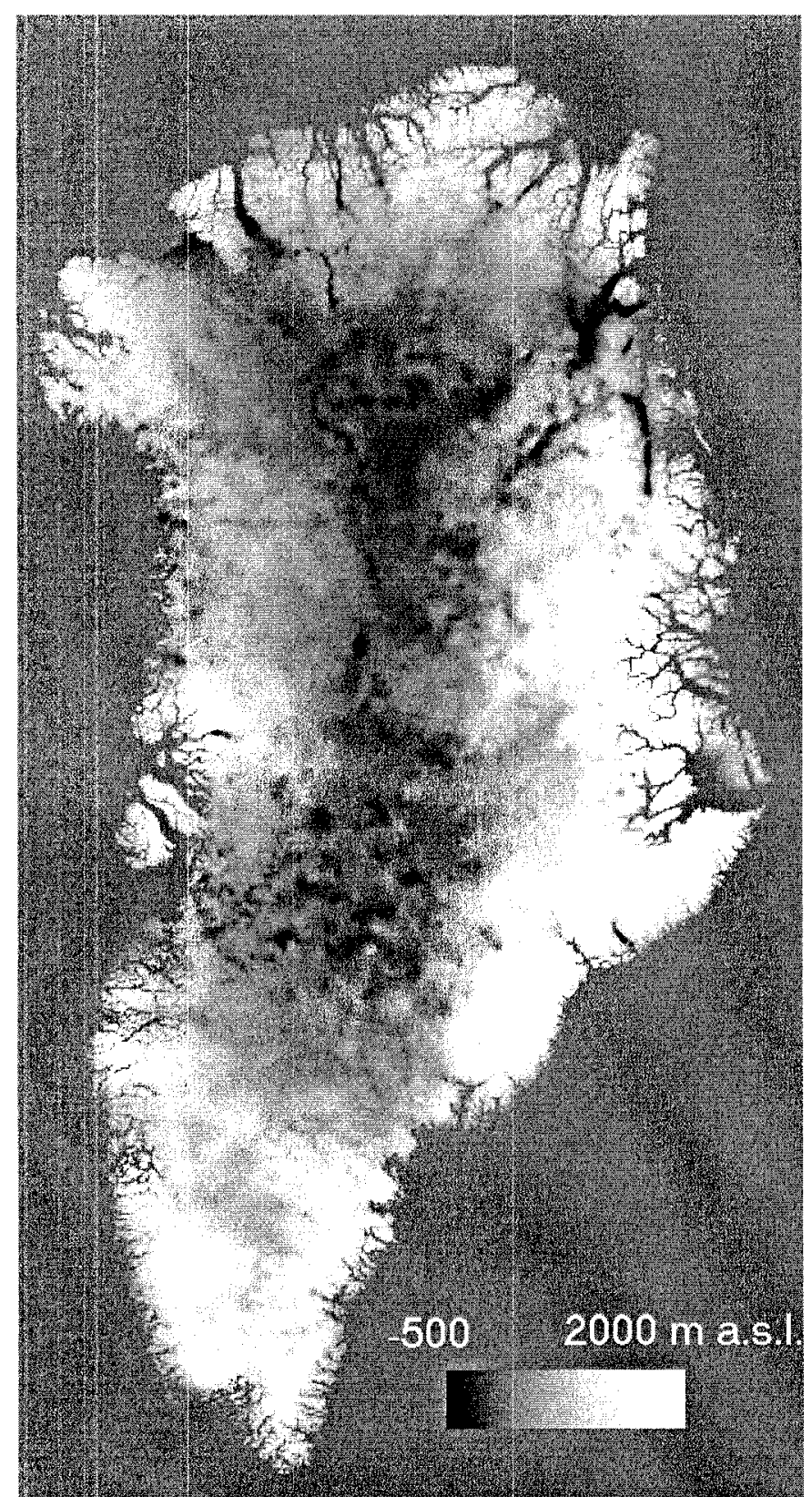

Figure 2: Bedrock topography. The background colour represents an elevation of $0 \mathrm{~m}$ a.s.l.

\section{BEDROCK REFLECTANCE}

Relative radar reflectances of the bedrock were extracted from the data by use of the peak returned power.

Compensation for the radar attenuation through the ice was not possible due to a lack of knowledge about the ice conductivity. It was, however, possible to identify areas of anomalously high reflectance, specifically the North East Greenland Ice Stream and these results will be published shortly.

\section{CONCLUSION}

This work describes how a significant new data set of ice thicknesses has been combined with one from the 1970's and the latest DEM to create the most accurate map of the topography of the Greenland bedrock. This will prove a valuable data set to the ice sheet modelling community and glaciologists working on Greenland.

\section{REFERENCES}

[1] Raju, G., W. Xin and R. K. Moore, "Design, Development, Field Observations and Preliminary Results of the Coheret Antarctic radar Depth Sounder (CARDS) of the University of Kansas, U.S.A.", Journal of Glaciology, Vol 36, No 123, pp 247-254, 1990.

[2] Gogineni, S., T. Chuah, C. Allen, K. Jezek and R. K. Moore "An improved coherent radar depth sounder", J. Glaciology, Vol 44, No 148, pp 659-669, 1998.

[3] Bogorodskiy, V. V., Bentley, C. R. and Gudmandsen, P. E., "Radioglaciology". Dordrecht, etc. D. Reidel Publishing Company, Kluwer Academic Publishers, 1985.

[4] GSLIB. Geostatistical Software Library and User's Guide', Second Edition, C. L. Deutsch and A. G. Journel, 1997.

[5] Bamber, J. L., S. Ekholm and W. B. Krabill, "A new, high-resolution digital elevation model of Greenland fully validated with airborne laser altimeter data", J. Geophys. Res. (in prep.). 